\title{
ENTRE DOIS GIGANTES: MELODRAMA E RELIGIÃO EM TELENOVELAS BRASILEIRAS
}

\author{
Between two giants: melodrama and religion in Brazilian telenovelas
}

Entre dos gigantes: melodrama y religión en telenovelas brasileñas

Marcos Vinicius Meigre e Silva

Doutorando em Comunicação Social - UFMG

marcosmeigre@hotmail.com

Simone Maria Rocha

Professora do Departamento de Comunicação Social - UFMG

simonerochaufmg@gmail.com

\section{Resumo}

$\mathrm{O}$ artigo discute como telenovelas espíritas figuram a experiência do final feliz típica do gênero telenovela e quais aspectos socioculturais são revelados pela televisualidade. Após apresentar elementos teóricos relacionados à conformação cultural do melodrama e da religião, destacamos a história do espiritismo no Brasil e, tendo na televisualidade o método operacionalizado pelo estilo televisivo, investigamos os eventos narrativos finais do último capítulo de A Viagem, Alma Gêmea e Além do Tempo. Constatamos que a morte atua como recurso narrativo para expansão dos enredos, usando de recursos estilísticos como cenografia e atuações para revelar traços da crença espiritualista brasileira da vida após a morte.

Palavras-chave: Televisualidade. Estilo televisivo. Telenovela.

\begin{abstract}
The article discusses how spiritist telenovelas feature the happy ending experience typical of the telenovela genre and which sociocultural aspects are revealed by the televisuality. After presenting theoretical elements related to the cultural conformation of melodrama and religion, we highlight the history of spiritism in Brazil and, having in televisuality the method operationalized by television style, we investigate the final narrative events of the last chapter of A Viagem, Alma Gêmea and Além do Tempo. We found that death acts as a narrative resource for the expansion of plots, using stylistic resources such as scenography and performances to reveal traces of the Brazilian spiritualist belief in life after death.
\end{abstract}

Key words: Televisuality. Television style. Telenovela. 


\section{Resumen}

El artículo analiza cómo las telenovelas espíritas presentan la experiencia de final feliz propia del género de las telenovelas y qué aspectos socioculturales son revelados por la televisualidad. Luego de presentar elementos teóricos relacionados con la conformación cultural del melodrama y la religión, enfatizamos la historia del espiritismo en Brasil y, tomando la televisualidad como método operacionalizado por el estilo televisivo, investigamos los hechos narrativos finales del último capítulo de A Viagem, Alma Gêmea y Além do Tempo. Verificamos que la muerte actúa como recurso narrativo para la expansión de las tramas, utilizando recursos estilísticos como escenografía y performances para revelar huellas de la creencia espiritualista brasileña en la vida después de la muerte.

Palabras clave: Televisualidad. Estilo televisivo. Telenovela.

\section{INTRODUÇÃO}

A produção ficcional brasileira é uma das mais aclamadas do mundo, num patamar de excelência e inovação singulares se considerarmos outros países onde a TV também alçou uma história similar. É a telenovela, em especial, o gênero que melhor figura a qualidade histórica com que a televisão se apropriou do melodrama enquanto matriz, não só demarcando aspectos da composição cultural do país como revelando traços de uma transnacionalização bem-sucedida do gênero (LOPES, 2004). Na vereda destas incursões, a telenovela brasileira sempre comportou debates que a aproximaram das matrizes culturais mais proeminentes na história do continente. E uma matriz em especial gravita em torno das ficções brasileiras: a religião.

A presença pública das religiões alarga os sentidos do campo a partir de diferentes espaços ocupados pela tematização da matriz religiosa brasileira (BITTENCOURT FILHO, 2003), constituída das misturas entre origens indígenas, portuguesas e africanas que selam o Cristianismo, bem como das contribuições de religiões como espiritismo, umbanda e budismo. Em sua reprodução simbólica, a comunicação religiosa deixou de ocupar somente a palavra escrita, tendo especialmente o cristianismo brasileiro se valido por muito tempo da literatura impressa como modelo de comunicação (CUNHA, 2019), para assumir lugares estratégicos em rádios e TVs em função do aspecto central da oralidade em nossa cultura. Da transmissão de eventos religiosos à conquista de canais próprios, as religiões sedimentam um terreno audiovisual em que é possível problematizar um avanço nos debates e refletir quanto aos processos interativos mídia-religião a partir da comunicação.

Admitindo melodrama e religião como duas matrizes culturais latinas e a centralidade da telenovela em nossa cultura, este trabalho questiona: como telenovelas espíritas figuram a 
experiência do final feliz típica de enredos melodramáticos e quais arranjos socioculturais se revelam pela televisualidade? Antes, no entanto, discutimos aspectos teóricos do melodrama e religião, do espiritismo e, em seguida, apresentamos os passos metodológicos e os resultados.

\section{DESENVOLVIMENTO}

\subsection{Melodrama e religião: notas para uma breve demarcação histórico-cultural}

Atrelado ao teatro popular da França do século XVIII, o melodrama clássico surgiu como "espetáculo total" para um público impedido legalmente de acompanhar encenações verbalizadas. Na ausência dos diálogos, o arcabouço expressivo e as marcas de atuação tornaram-se alternativas para as peças populares, compreendidas como "lugar de chegada de uma memória narrativa e gestual populares, e lugar de emergência de uma cena de massa" (MARTIN-BARBERO, 1992, p. 41 - tradução nossa). Impedidos de falar, o apelo gestual possibilitou uma alternativa viável às encenações, tidas como exaltadas:

A retórica do excesso, na qual tudo tendia ao esbanjamento, desde a encenação de efeitos visuais e sonoros até a estrutura dramática de sentimentos exacerbados, era uma vitória contra a repressão, contra uma certa economia da ordem, da poupança e da retenção cultivada por qualquer "espírito culto" (BRAGANÇA, 2007, p. 34)

Martín-Barbero $(1992,2013)$ pondera que em sua estrutura fundante, o melodrama se assenta nos sentimentos do medo, entusiasmo, tragédia e riso, dos quais emergem sensações terríveis, excitantes, ternas e jocosas, personificadas no traidor, justiceiro, vítima e bobo. Este arranjo se dá sob duas premissas: esquematização e polarização, sendo os personagens convertidos em signos vazios e a uma redução valorativa maniqueísta (bons x maus).

Na América Latina, o melodrama resultou em algo mais do que um gênero dramático, ou seja, resultou em uma matriz cultural que alimenta o reconhecimento popular na cultura de massas, território-chave para estudar a não-simultaneidade do contemporâneo como chave das mestiçagens de que somos feitos. Porque, como nas praças populares de mercados, no melodrama está tudo resolvido, as estruturas sociais e as do sentimento, muito mais do que somos - machistas, fatalistas, supersticiosos - e do que sonhamos ser, a nostalgia e a raiva (MARTÍN-BARBERO, REY, 2001, p. 151-152)

Herlinghaus (2002, p. 23 - tradução nossa) compreende o melodramático como um conceito de busca e o define não como redução a temas ou gêneros, mas como "uma matriz da 
imaginação teatral e narrativa que ajuda a produzir sentido em meio às experiências cotidianas de indivíduos e grupos sociais diversos". Peter Brooks, a seu turno, interpreta que no melodrama pairam excessos de sentimentos, exaltações nas encenações, a pantomima como estética de expressão que, em alguma medida, se vinculam às dinâmicas de sacralização.

O melodrama representa tanto o desejo de ressacralização quanto a impossibilidade de conceber a sacralização de outra forma que não em termos pessoais. $\mathrm{O}$ bem e o mau melodramáticos são altamente personalizados: eles são atribuídos, habitam pessoas que de fato não têm complexidade psicológica, mas que são fortemente caracterizadas (BROOKS, 1995, p. 16 - tradução nossa)

As atuações no melodrama carregam consigo associações que pretendem interligar os aspectos éticos aos trejeitos definidores dos personagens, aproximando valores morais das condições de agir dos sujeitos. Baltar (2019) considera o melodrama como uma concepção de mundo, para além de um gênero consagrado, articulando relações polarizadas em nome de uma estética da exacerbação - com dramatizações hiperbólicas - voltada à mobilização sentimental. É nesse sentido que pensar uma imaginação melodramática (BROOKS, 1995) transpõe barreiras de gêneros, formatos e suportes para abrir-se a diferentes vertentes e compreender como o melodrama foi capaz de historicamente ocupar narrativas impressas, televisivas, radiofônicas, em condição intermidial (HERLINGHAUS, 2002).

Localizando no melodrama uma catarse que "purifica e liberta dos sentimentos de iniquidade e pecado, e permite que o espectador se contemple em suas imagens enobrecidas" (MONSIVÁIS, 2002, p. 106 - tradução nossa), Monsiváis afirma que melodrama e religião se mesclam e, para exemplificar, indica a visão destas matrizes quanto à pobreza: no melodrama, é dever do pobre suportar o sofrimento, similar à resignação pregada pelas religiões com a compensação futura, no pós-morte. A culpa do sujeito no cristianismo cria uma "ambivalência que sustenta o modo narrativo melodramático: a asfixia erotizada, o desejo que está ligado ao autossacrifício, a morte que promete salvação" (OTT, 2002, p. 255 - tradução nossa).

Quanto à religião, nosso país é exemplo do que Peter Berger identificou na realidade contemporânea do mundo, que segue "furiosamente religioso como sempre foi, e em alguns lugares mais do que nunca" (BERGER, 2001, p. 11). Para ele, secularização significava dizer que "a modernização leva necessariamente a um declínio da religião, tanto na sociedade como na mentalidade das pessoas" (BERGER, 2001, p. 10). Mas o autor assumiu o equívoco da tese e ponderou que as religiões vivem experiências distintas nas sociedades. Em verdade, 
Ao contrário do que se pensava anteriormente, hoje é mais clara a noção de que a modernidade não gera secularização. Em vez disso, a quebra do "dossel sagrado" levou a um pluralismo religioso crescente, ao estabelecimento de um mercado religioso, a escolha religiosa privada e ao posicionamento do indivíduo como fonte de significado (ROCHA, VASQUEZ, 2014, pp. 19-20)

Atenta à diversidade do cenário religioso brasileiro, a comunicação massiva, quando se apropria de aspectos religiosos em suas narrativas midiáticas, evidencia a complexidade da matriz religiosa brasileira e, neste texto, buscamos articular ao espiritismo, religião tratada na próxima seção.

\subsection{Notas sobre o espiritismo: o lugar de uma minoria religiosa no contexto brasileiro}

De influência positivista, o espiritismo apareceu no século XIX, em salões parisienses onde se viam "mesas girantes", experiências de levitação de objetos sem aparente explicação científica. O cientista e pedagogo Hippolyte Léon Denizard Rivail (Allan Kardec) conduziu experimentos sobre os casos e os relacionou a bases científicas, com arcabouço procedimental racional. A partir daí, sustentando-se no tripé ciência, filosofia e religião, o espiritismo expandiu, na Europa, as dimensões científica e filosófica, e no Brasil, as manifestações religiosas. Por aqui, há uma construção singular da doutrina: seja pela atuação de grupos médicos e repressões (GIUMBELLI, 1997), pela necessária adequação de princípios quando inseridos em novas áreas e reinterpretados por valores de novas culturas (STOLL, 1999), ou pelas lutas internas de grupos que reverberam sobre o que conhecemos por espiritismo (DAMAZIO, 1994).

Em suas bases constitutivas, "o Espiritismo é, pois, a doutrina fundada sobre a existência, as manifestações e os ensinamentos dos espíritos" (KARDEC, 2007, p. 186). Em suas máximas, o espiritismo estabelece a crença em Deus, imortalidade da alma (o espírito sobrevive à finitude da matéria), reencarnação (nova vida em novo corpo), existência de espíritos (seres invisíveis dotados de inteligência), comunicação com o mundo invisível (mediunidade, ação de pessoas aptas a receber mensagens dos espíritos), pluralidade de mundos habitados (vida inteligente em outros planetas) e evolução moral (KARDEC, 2007).

Além disso, seu caráter anticlerical conjugado à experimentação científica agradava a parcelas de ilustrados nacionais, expandindo-se entre a elite letrada. A partir do lugar centralizador da Federação Espírita Brasileira (FEB), a religião espírita se consagrou como uma doutrina assentada na caridade, no assistencialismo aos mais pobres e na prescrição de 
tratamentos mediúnicos. Lutas políticas, movimentos de repressão e embates jurídicos marcaram a história da religião em mais de um século no Brasil, sendo hoje uma das principais religiões no país. Segundo IBGE (2010), o espiritismo conta com 3,8 milhões de adeptos, a maioria de classes altas e cultas, o que referenda a tese de ser "uma religião letrada, no sentido de seu enraizamento em temas e emblemas que caracterizam a modernidade Ocidental desde o século XIX [...]" (LEWGOY, 2000, p. 12).

Dentre as adaptações do espiritismo no Brasil, nomes como o de Francisco Cândido Xavier (Chico Xavier) ajudaram na propagação doutrinária, difusão de preceitos religiosos e popularização de uma cultura religiosa assentada em valores afeitos ao cristianismo. Nessa dinâmica, a literatura espírita tornou-se um chamariz de sucesso para a expansão doutrinária, valendo-se da importância que o estudo das obras tem para o espiritismo e materializando nos romances espíritas um filão crescente no mercado editorial:

Num momento em que a inserção na mídia, em especial a televisão, se destaca como fator de divulgação doutrinária, constituindo um novo campo de disputa no espaço público, o Espiritismo vem alargando sua inserção social, especialmente entre os segmentos da classe média, por meio do investimento no campo literário (STOLL, 2004, p. 181).

Como parte da socialização do imaginário religioso, os romances espíritas fazem coro ao exercício da leitura como mote do habitus espírita, num mercado que já arrecadou mais de 500 milhões de reais ao ano (SUPERINTERESSANTE, 2012). Ao lado de Chico Xavier, engrossam a lista de médiuns projetados nacionalmente a partir da publicação de romances espíritas nomes como Zíbia Gasparetto e Divaldo Franco.

\subsection{O método da televisualidade para a especificidade do meio televisivo}

Em nosso estudo sobre telenovela, adotamos a televisualidade como proposta teóricometodológica. Televisualidade combina noções da visualidade (MITCHELL, 2009) ao estilo televisivo (BUTLER, 2010) para considerar as especificidades da TV (WILLIAMS, 2016) e revelar traços da organização sociocultural, demandas mercadológicas, práticas cotidianas etc. (ROCHA, 2019). O método se refere à maneira pela qual o texto televisivo evidencia questões da cultura, como obras televisivas se oferecem enquanto experiência visual e cultural ao telespectador (ROCHA, 2019). Em síntese, o conceito compreende

[...] as determinações culturais da experiência visual específicas do meio televisual. Falar em televisualidade implica convocar uma rede complexa que envolve os instrumentais técnicos de produção e reprodução, as instituições sociais, a cultura televisiva, as formas de figuração do mundo e a presença do observador/espectador (ROCHA, 2019, p. 33-34) 
Por esta razão, convocar a televisualidade como aporte para a pesquisa nos conduz a dois movimentos: atenção à materialidade televisual das produções, com foco nas combinatórias de imagem e som servindo a propósitos narrativos (elementos materiais do texto televisivo); e identificação de aspectos socioculturais revelados pelos recursos estilísticos na produção de sentidos (elementos externos ao texto de TV).

Para lidar com as características materiais do meio televisivo, a televisualidade toma de empréstimo Jeremy Butler e sua proposta de estudo do estilo televisivo, que diz da combinação entre imagem e som exercendo funções na TV. Butler (2010) operacionaliza a metodologia estilística em 4 etapas: descritiva, analítica/funcional, histórica e avaliativa ${ }^{1}$. Descrever, para ele, é fragmentar o audiovisual em sintagmas, procedimento que remete a uma "engenharia invertida". A dimensão analítica/formal diz dos propósitos do estilo, podendo denotar, expressar, simbolizar, decorar, persuadir, saudar/interpelar, diferenciar e significar imediatismo. Por fim, a evolução histórica do estilo é captada no recuo em programas de um mesmo gênero para reconhecer as alterações.

Assim, além de reconhecermos as especificidades da TV, entendemos o meio como mediação em que "o que se produz na televisão não responde unicamente a requerimentos do sistema industrial e a estratagemas comerciais, mas também a exigências que vêm da trama cultural e dos modos de ver" (MARTÍN-BARBERO, 1992, p. 20). Pensar a trama cultural como um dos fatores que exige da televisão processos de inovação e rupturas, transformações e reconfigurações, significa apontar para a relevância dos traços socioculturais que jogam papel na construção televisiva, tais como as questões religiosas.

\subsection{As telenovelas em questão: delimitação dos eventos narrativos}

O uso da nomenclatura telenovela espírita leva em conta um entendimento de gênero televisivo enquanto categoria cultural (MARTIN-BARBERO, 2013), de modo que ao adotarmos esta expressão, consideramos a emergência de um subgênero ficcional assim denominado por críticos de TV, estudiosos e audiência em geral. Ao taxarmos de telenovelas espíritas um conjunto de ficções das últimas décadas na TV brasileira, amparamo-nos nesta visão de gênero televisivo, que reflete sobre o objeto em sua circularidade e interações. As telenovelas espíritas têm sido um filão na dramaturgia nacional que incorporou crenças espiritualistas genéricas e fez dialogar preceitos religiosos com marcas do melodrama.

\footnotetext{
${ }^{1}$ Apontada por Butler (2010) como uma dimensão problemática e ainda pouco desenvolvida, não trataremos neste texto da etapa avaliativa.
} 
Este conjunto de telenovelas povoa a televisão brasileira desde a década de 1960, quando teve início a telenovela diária no Brasil. Em seus primeiros passos, o subgênero surgiu a partir de romances mediúnicos, com Somos Todos Irmãos, adaptação da TV Tupi do romance espírita $A$ vingança do judeu, lembrada como a primeira telenovela espírita, numa fase em que menos se podia discutir conformação do subgênero e mais apontar a um protótipo de telenovela espírita que se consolidaria anos depois. Desde então, não só outros textos da literatura espírita serviram de base para produções ficcionais (as obras espíritas Nosso Lar e $E$ a vida continua... sustentaram a criação de $A$ Viagem), como também emergiram textos inéditos, combinados a inovações estilísticas e narrativas. Do surgimento atrelado ao romance espírita, estas telenovelas desenvolveram padrões e esquemas próprios para seus enredos, revelando na historicidade do subgênero uma gravitação entre fases de maior fidelidade da ficção a preceitos doutrinários (A Viagem, por exemplo), outras fases em que prevalecia uma abordagem generalista sobre espiritualidade (exemplo $O$ Profeta), e outras em que se nota a consolidação (nos anos 1990) e expansão do subgênero, tendo seu auge nos anos 2010.

Tais pontos quanto ao subgênero nos servem para localizar culturalmente a telenovela espírita na trama ficcional brasileira e demonstrar como este conjunto de produções se capilarizou ao longo das décadas na TV, solidificando-se nos últimos vinte anos. Por esta razão, concentramo-nos neste período em que temos um subgênero já estruturado para investigar a televisualidade de algumas produções. Trazemos as telenovelas A Viagem, Alma Gêmea e Além do Tempo a fim de captar nuances da abordagem religiosa pelo viés melodramático da ficção ao longo das últimas décadas, escolhidas por serem de décadas diferentes e produzidas por equipes de roteiristas distintos.

A Viagem é uma telenovela de Ivani Ribeiro, colaboração de Solange Castro Neves, levada ao ar na TV Globo de 11 de abril a 22 de outubro de 1994, às 19 horas. Remake da obra homônima de 1975 da TV Tupi, narra a vida de Alexandre (Guilherme Fontes), um jovem rebelde que se suicida na prisão após ser condenado por assassinato. Do plano espiritual, passa a agir sobre os que lhe prejudicaram, atrapalhando a vida de Otávio Jordão (Antônio Fagundes) e sua relação amorosa com Diná (Christiane Torloni), irmã de Alexandre. Trama de maior sucesso das 19h nos anos 1990, foi reprisada duas vezes em Vale a Pena Ver de Novo (1997 e 2006) e duas vezes no canal Viva (2014 e 2021).

Alma Gêmea foi escrita por Walcyr Carrasco para as 18 horas da TV Globo, no ar de 20 de junho de 2005 a 10 de março de 2006. Traz como eixo central a trama romântica de Luna (Liliana Castro) e Rafael (Eduardo Moscovis) que, após a morte precoce da moça, passa 
a viver isolado cultivando rosas. Luna reencarna como Serena (Priscila Fantin), índia que pressente ter uma missão em São Paulo. O casal sofre diante das investidas de Cristina (Flávia Alessandra), que tenta a todo custo conquistar Rafael. A obra foi o maior sucesso da década na faixa, por vezes ultrapassando a audiência de novelas inéditas, algo que também aconteceu quando exibida no Vale a Pena Ver de Novo, em 2009.

Por fim, Além do Tempo é uma trama de Elizabeth Jhin para as 18 horas da TV Globo, levada ao ar de 13 de julho de 2015 a 16 de janeiro de 2016. Conta a história de amor entre Lívia (Aline Morais) e Felipe (Rafael Cardoso) que, impedidos de se unirem no século XIX, reencarnam no século XXI e seguem na busca pela chance do amor. A trama trouxe uma abordagem inédita ao se fragmentar em duas fases separadas por 150 anos: a primeira em 1850 e a segunda nos dias atuais, com a reencarnação de todos os personagens do século XIX para resgates do passado. Tida como ousada, obteve bons índices de audiência no horário.

Como corpus empírico, coletamos a sequência final de cada obra, no último capítulo, analisando o desfecho das produções em seu último ato, quando desponta o final feliz. Denominamos eventos narrativos os entrechos em que há micro-histórias atreladas ao enredo principal e estruturadas como subtramas que garantem o avançar da narrativa (ROCHA, ALVES, OLIVEIRA, 2016). Tais segmentos estudados pela televisualidade exigem uma decupagem atrelada à análise funcional e podem revelar traços materiais e imateriais do texto televisivo, o que neste caso nos ajuda a compreender a relação entre mídia e religião.

\subsubsection{A Viagem}

Em A Viagem, o fim da trama se dá numa caverna bem iluminada, onde aparecem Otávio e Diná. A composição cênica denota a inserção dos personagens num universo reservado apenas a eles, onde terão a possibilidade de comunhão efetiva e duradoura. Primeiramente é o espírito de Otávio a surgir, sob efeito visual esbranquiçado até se formar a figura completa dele, enquadrado de corpo inteiro e, na sequência, o rosto em primeiro plano. Otávio olha ao longe, pelo interior da caverna, e o plano seguinte apresenta outras dimensões do espaço, para onde ele caminha (Figura 1).

Os planos gerais que acompanham o caminhar de Otávio denotam a diminuta proporção do sujeito perante a magnitude do composto ao redor: de branco, mas visto pelas sombras, Otávio se mistura ao ambiente, numa simbiose que quase o integra ao espaço e dificulta reconhecê-lo. A soberania do espaço se impõe ao intento de singularizar o sujeito em cena, numa alusão ao que se reserva aos seres na dimensão espiritual. 


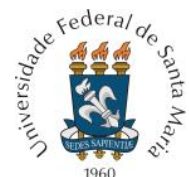

PROGRAMA DE PÓS-GRADUAÇÃO EM COMUNICAÇÃO DA UNIVERSIDADE FEDERAL DE SANTA MARIA

Quando Otávio interrompe a caminhada, ele avista a chegada de Diná, que vem em sentido oposto (Figura 2). A troca de olhares entre ambos segue o clássico modelo de planos, um plano geral os reduz diante da gigantesca composição rochosa (Figura 3) e um plano de detalhe capta o momento em que eles dão as mãos (Figura 4): o amor permanece selado no plano espiritual. A gestualidade do dar as mãos não apenas simboliza a consagração do amor romântico concretizado entre o casal, mas expressa a possibilidade de ocorrência na dimensão espiritual, no pós-morte física. Eles sorriem e se entreolham, seguros de que a afetividade os mantém unidos e partem caminhando juntos, enquanto o cântico suave dá lugar à narração off.
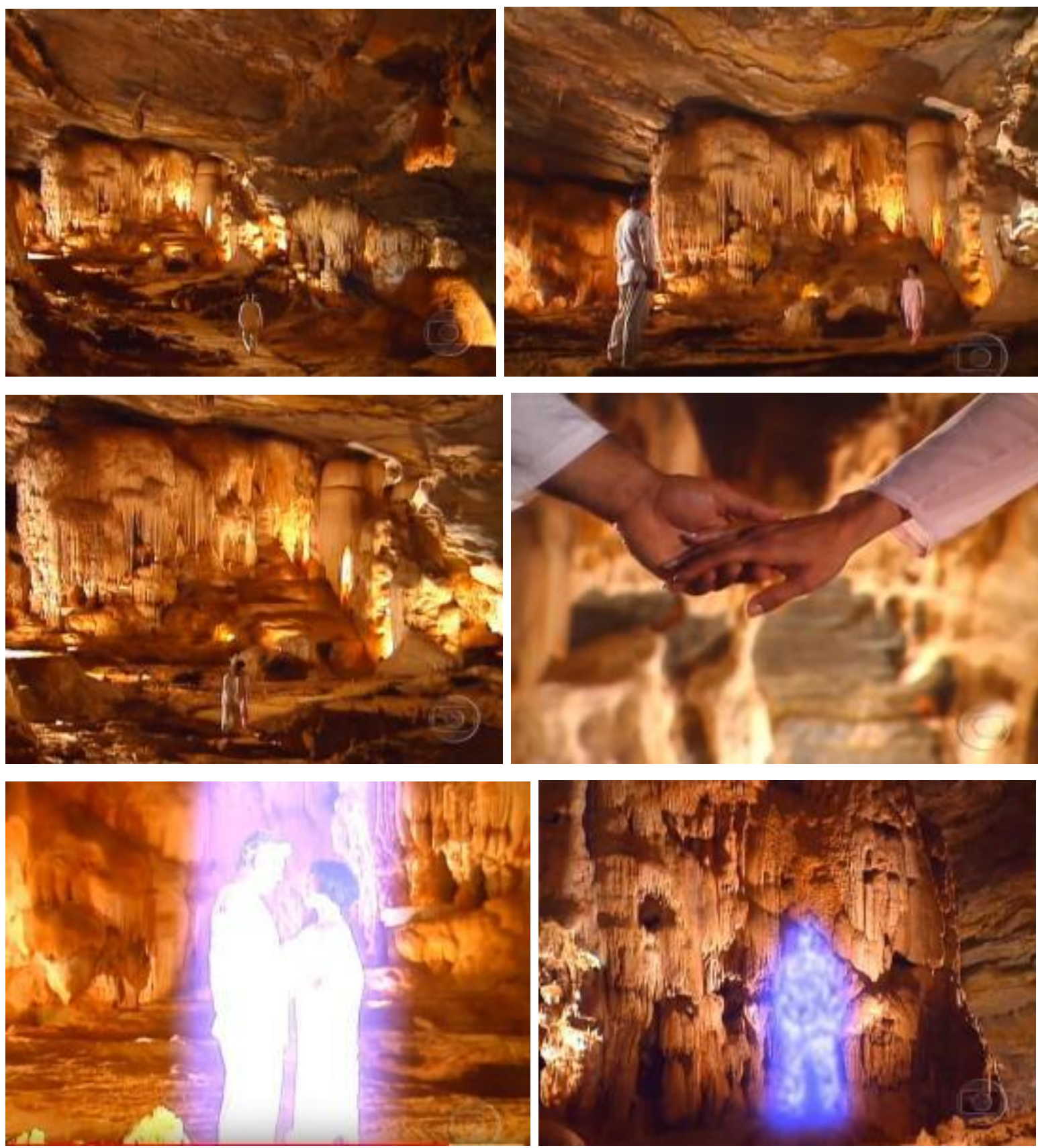
Figuras 1-6: O casal protagonista de $A$ Viagem no plano espiritual Fonte: Reprodução TV Globo

O casal caminha e se posta lado a lado, vistos num plano geral que evidencia um feixe luminoso surgido do alto e em direção aos dois. A luminosidade se intensifica, esbranquiçada, envolve Diná e Otávio, que passam a ser captados em primeiro plano enquanto se mostram mais claros (Figura 5). Tal composição visual expressa a dimensão evolutiva dos personagens e a aura de bondade, serenidade e pacifismo que os cerca: puros e livres para a marcha do amor em outra esfera. Dentro do melodrama clássico, são eles os bons da narrativa. Seguemse planos de detalhe apresentando os personagens enquanto se entreolham, admirando-se.

O casal se abraça, fundem-se numa única branquidão, integram-se como a figurar a concepção máxima do amor realizado (Figura 6). O efeito esbranquiçado se esvai pelo ar, atinge o alto e se encerra a claridade que tomava o espaço. Enquanto estiveram lado a lado, os dois não trocaram palavras, mas firmaram contato visual e gestual. Numa associação ao melodrama clássico, os silêncios primitivos que caracterizavam as encenações se voltaram potentes neste evento da telenovela. Neste caso, o não-verbal referenda a importância da visualidade na composição das tramas. Encerrando a sequência, passa-se a dimensionar o lado externo da caverna, por onde a luz sobe até atingir as estrelas. No espaço escuro estrelado, surge uma grande luz ao centro, que domina o quadro visual acompanhada pela palavra FIM.

Em A Viagem, o casal não encerra a trama após a imediata morte. Pelo contrário, encontravam-se no plano espiritual desde meados da obra. Assim, a consagração do amor romântico estava selada desde momentos prévios, no plano espiritual, e o que ocorre neste evento final é a fusão dos seres, corpos etéreos, espíritos já em união precedente. A morte, em A Viagem, adensava o roteiro do casal central, mas nem por isso abalou os modelos narrativos da trama, que seguiram a lógica de consagração do amor ao encerrar o enredo. Ao fim, o amor permaneceu intocável e referendou a aura superior do sentimento que unia os protagonistas, visual e espiritualmente, dado que o casal selou sua purificação de almas e prosseguiu aos céus, sem uma localização exata para onde partiram quando transformados em feixes de luz. O amor, neste caso, é visualmente uma luz, que viaja pelo espaço quando sacramentado entre dois seres de afeto partilhado. Em A Viagem, o amor romântico saiu consagrado e vitorioso, mesmo que, para tal, tenha incorporado à narrativa a lógica das vidas espirituais, do plano espiritual como esfera de sobrevivência para onde os seres são conduzidos no pós-morte. Não fosse a inserção deste preceito religioso como recurso narrativo, o casal central não seria visto em seus momentos derradeiros de união afetuosa. 


\subsubsection{Alma Gêmea}

Em Alma Gêmea, o evento narrativo final traz Serena e Rafael do lado de fora da mansão do casal, após Rafael ser atingido por um tiro disparado por Cristina, sua ex-esposa. Rafael, ao chão, esboça expressões de angústia e sofrimento, amparado por Serena. Ao redor, o plano geral capta a movimentação dos presentes, a casa em chamas ao fundo e o caos instaurado. Uma sequência de planos define a conversa derradeira entre os dois, com primeiríssimos planos nos fazendo compactuar com a mensagem de amor final entre eles.

A intensa dor de Rafael sacramenta sua morte, seguido por um colapso em Serena, que também morre a seu lado. Ambos caídos, comovem os presentes, sob trilha funesta. De repente, os espíritos dos dois se desprendem dos corpos inertes, levantam-se e caminham em direção à câmera, de mãos dadas, vistos sob efeito visual esbranquiçado. Dali em diante, o casal não mais troca palavras.

O plano geral expressa que os espíritos seguem sem se influenciar pelo caos deixado para trás, enquanto os parentes tentam reanimá-los. É ainda por meio do plano aberto que vemos, ao fundo, a casa em chamas (Figura 7). Ali dentro, a vilã Cristina morrera e fora tragada pelo espelho para acompanhar o "Diabo" que a veio buscar, já que ela lhe prometera a alma no passado. A casa é a materialização do imaginário sociocultural sobre inferno, com labaredas ardendo sobre os maus. Caminhando em sentido oposto (Figura 8), Serena e Rafael vão a outra dimensão, destinada a seres de luz que se conduzem ao céu. O imaginário popular de céu e inferno ${ }^{2}$, dicotomia tão bem demarcada na cultura religiosa, é uma das provas de que a secularização latina se organiza sob outras lógicas. Dicotomias adequadamente cabíveis a enredos melodramáticos que se sustentam na esquematização e polarização (MARTINBARBERO, 2013) para conduzir suas tramas.

No desenrolar do evento narrativo, o casal, de mãos dadas, esvai-se por toda a tela esbranquiçada e, no plano seguinte, surgem dentro de uma espécie de gruta ou caverna, onde há um lago no qual uma rosa está projetada. A rosa era o símbolo do amor do casal, desde encarnações anteriores, e estar ali simbolizaria a consagração do amor romântico. De frente um para o outro (Figura 9), pronunciam, cada um a seu tempo, a palavra "eternidade" e uma

\footnotetext{
2 Ainda que a concepção de inferno, como no imaginário cristão, não seja um pressuposto do espiritismo, é importante considerar como a telenovela trabalha com este valor cultural-religioso. Ademais, a visão espírita sobre este tema pode ser localizada numa das obras básicas da doutrina, intitulada $O$ се́u e o inferno.
} 
sequência de corporeidades novas desfila em tela: são encarnações pregressas de ambos, em que já foram índios, freiras, lordes, ciganos, escravos, lavradores, samurais (Figura 10).

Após a sucessão de encarnações, o casal retoma as feições de Rafael e Serena, sob efeitos esbranquiçados, dão as mãos (Figura 11) e, unidos, tornam-se uma única luz que ocupa o centro visual e atinge o topo da caverna. O encerramento da trama se dá quando, em 2006, um casal de crianças se encontra casualmente no parque e, no jogo de planos, revela a sintonia entre ambos. Sorriem juntos e, perguntado pela garota qual era seu nome, o menino responde "Rafael", ao que a trilha se intensifica, os sorrisos de ambos também e a trama consagra uma nova existência para o casal (Figura 12).
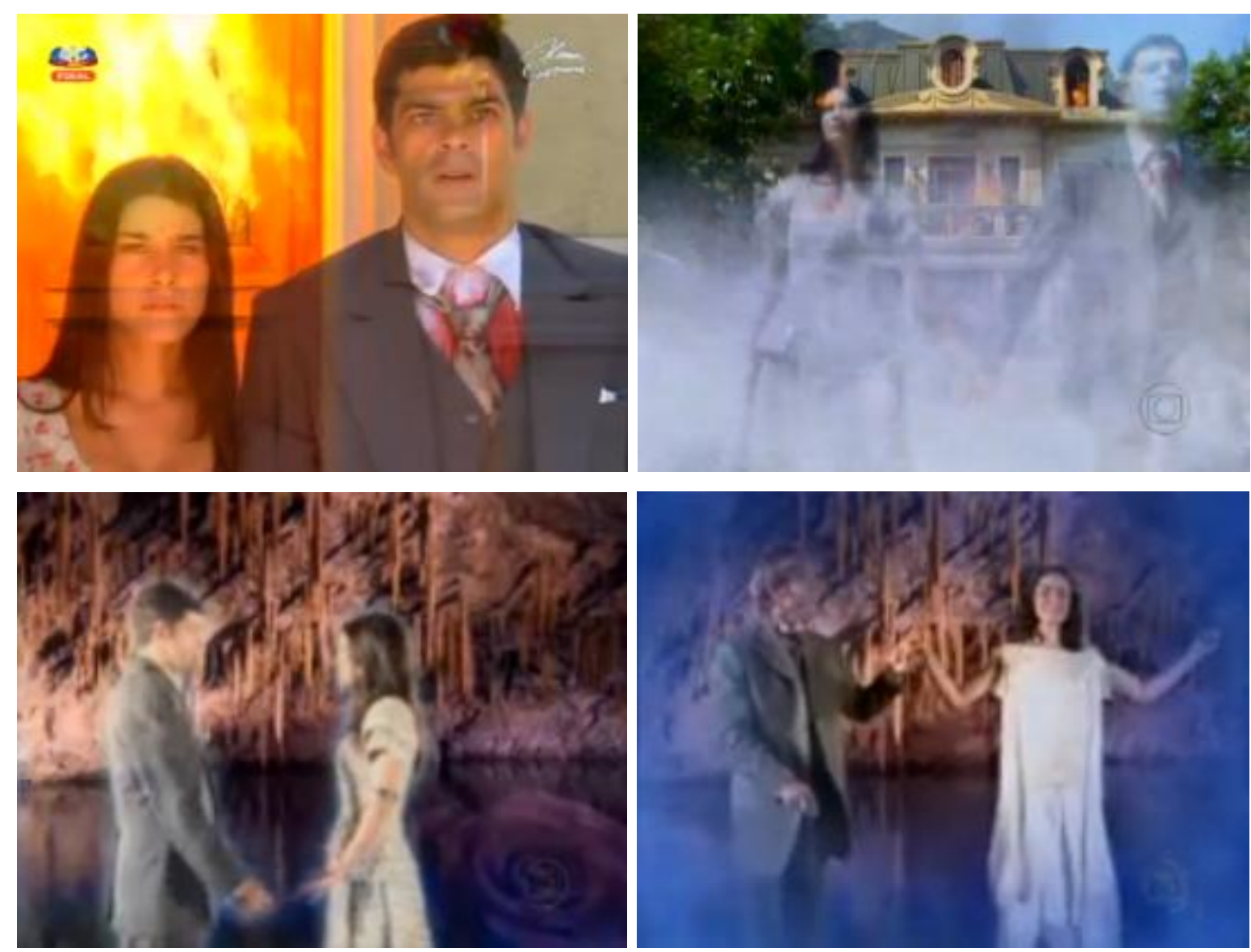

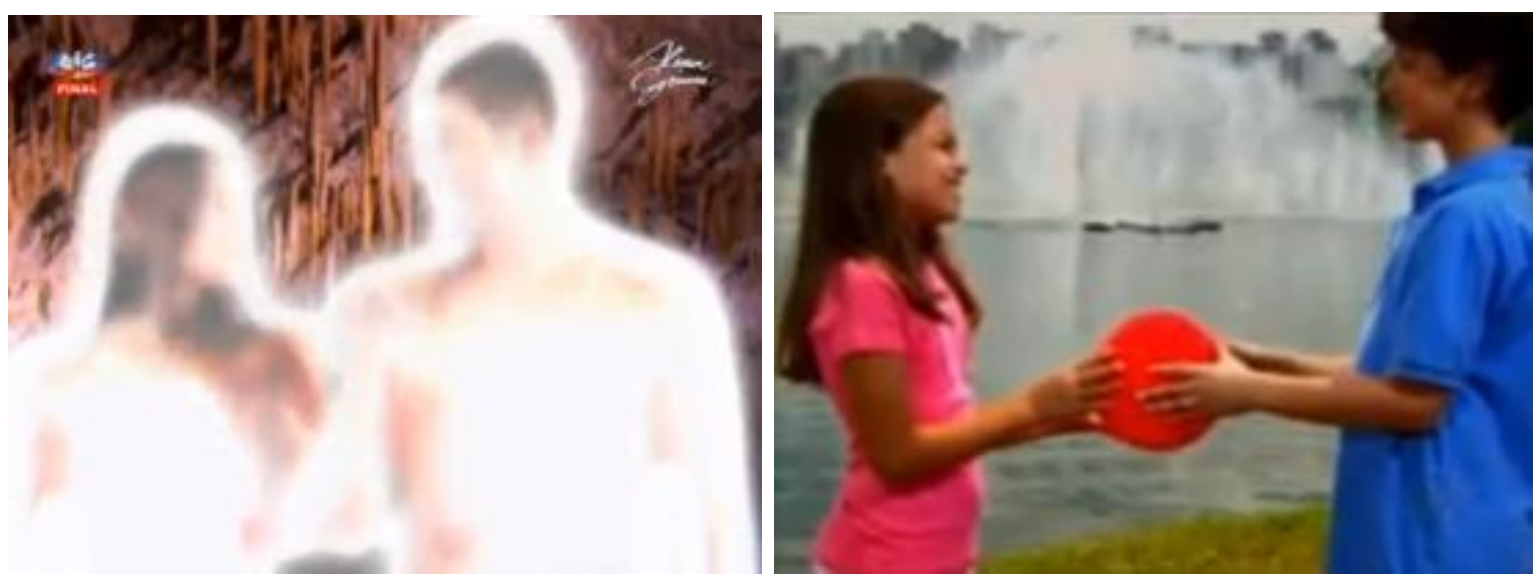

Figuras 7-12: O casal protagonista em diferentes encarnações em Alma Gêmea Fonte: Reprodução Canal SIC

Alma Gêmea optou por solucionar o entrave do amor impedido pela morte num curto espaço de tempo. Enquanto A Viagem trabalhou de maneira diacrônica, Alma Gêmea fez a diegese avançar e/ou recuar conforme os recursos estilísticos empregados: tanto a composição de figurinos delimitava a caracterização dos tempos nas diferentes vidas como as passagens de tempo demarcadas por geradores de caracteres e novas ambientações (na sequência final tem-se "São Paulo, março de 2006" na tela). No cruzamento entre passado, presente e futuro das vidas tratadas, o principal objetivo é atender ao inevitável encontro entre as duas almas, que não alcançaram a plenitude do amor romântico ao longo de 227 capítulos de lutas e entraves, mas ao fim, após a morte, conseguiram fortalecer-se enquanto casal, unidos, sempre de mãos dadas, atingindo o auge do roteiro melodramático e do modelo de amor romântico.

A telenovela adensou esquemas já vistos em A Viagem quanto a figurações espíritas, reverberando efeitos visuais para apresentar seres espirituais, reencarnações, além de elementos cênicos para caracterizar o plano espiritual. Em termos de atuação, a gestualidade do "dar as mãos" também foi replicada a fim de substanciar a temática romântica afeita ao melodrama. Na cenografia, a repetição da gruta/caverna como espaço para onde os seres espirituais vão no pós-morte denota uma imaginação cultural religiosa atrelada ao misticismo, ao desconhecimento preciso do "para onde vamos". Com replicações, Alma Gêmea e A Viagem estiveram estilisticamente próximas nos modos de composição das tramas em torno da espiritualidade e da construção televisual do espiritismo. 


\subsubsection{Além do Tempo}

Nesta obra, o evento final traz os protagonistas Lívia e Felipe à beira de um penhasco, abraçados e felizes. Uma narração off acompanha o beijo do casal e não há testemunhas daquela união a não ser as montanhas e o céu. Diminutos, a ampliação do campo visual torna mais evidente o espaço físico ao entorno e comprova visualmente que o casal está a sós (Figuras 13-14). Esta captação se justifica para diferenciar-se do final trágico na primeira fase da trama: em um penhasco, eles foram atacados por Pedro (Emilio Dantas), que os matou no século XIX. Agora, reencarnados no século XXI, estavam finalmente a sós para viver o amor que se viu interrompido há mais de um século.
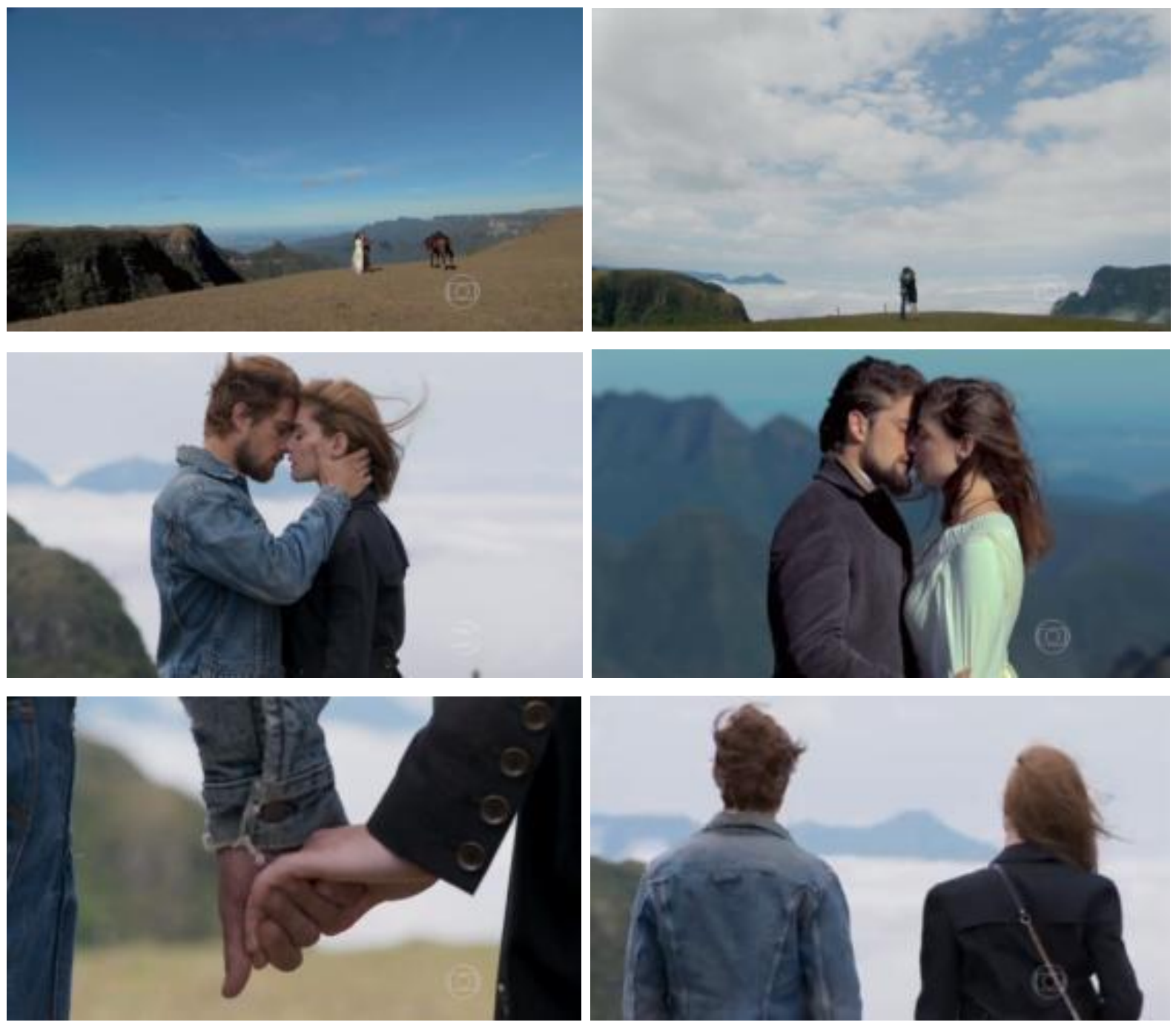

Figuras 13-18: Lívia e Felipe em diferentes encarnações em Além do Tempo Fonte: Reprodução Globoplay 
O casal não pronuncia uma única palavra, apenas abusam dos olhares. Mas, enquanto se beijam, há flashes sucessivos que transportam o espectador ao universo diegético do século XIX, para acompanharmos os dois na mesma condição - aos beijos (Figuras 15-16). Apenas os elementos sonoros - um efeito tal qual rajada de vento - e a composição de figurinos são os denotadores das épocas distintas, separadas na diegese por mais de cem anos. Neste pacto com o público, a narrativa se encerra sem remeter a plano espiritual ou à condução a novas esferas do mundo superior (como nas novelas anteriores). Aqui, seja na exibição dos personagens no presente, seja na rememoração em flashbacks que os situam na vida passada, não há figuração de espíritos, espaços cênicos etéreos ou ambientes celestiais no pós-morte. O céu é elemento cênico que eles miram, mas o céu real, a concretude celeste, não a metaforização das tramas anteriores (Figuras 17-18).

Tratou-se, portanto, de uma importante ruptura em termos esquemáticos ao debater aspectos de crenças espiritualistas. Enquanto as tramas anteriores consolidaram um repertório estilístico de figuração didático-instrucional em torno da temática espiritualista, Além do Tempo trouxe artifícios da montagem, figurino e sonorização como aportes para simbolizar vidas passadas. Em termos narrativos, a divisão em dois tempos da trama permitiu que o amor romântico se visse flagelado ao final da primeira fase, mas concretizado ao final da segunda, ofertando a compensação para o público (MARTIN-BARBERO, 2013) e não rompendo com as expectativas de união feliz e exitosa para o casal principal.

Além do Tempo é, narrativa e visualmente, distinta das predecessoras e não se sustenta na mesma lógica de efeitos para tornar visível elementos etéreos. A resolução do impasse de um amor interrompido em vidas pregressas é solucionada sob a lógica reencarnacionista sem, no entanto, convocar a dimensão de mundos espirituais para a esfera do visível. Em termos narrativos, o amor se soluciona e impulsiona o desenrolar do melodrama de uma existência até outra. Ao fim, são ativadas estas memórias passadas para consolidar a união do casal e carimbar a vitória do amor romântico como eixo central do universo melodramático.

\section{CONSIDERAÇÕES}

\subsection{O que revelou a televisualidade? A morte como final feliz nas telenovelas espíritas}

No imaginário social brasileiro, as matrizes culturais religiosas estão assentadas na dicotomia entre valores - bem e mal, céu e inferno - como visto na narrativa das novelas. O melodrama, por sua vez, enquanto matriz que sedimenta saberes e modos de ler o mundo, 
obedece a aspectos que conduzem à pacificação do público, satisfazendo-se com as considerações ofertadas. Nas telenovelas espíritas, o cruzamento do melodrama com a dimensão religiosa se processa em alusão ao histórico cultural latino, operando em termos estilísticos e narrativos para consagrar ambos os campos. Quanto ao estilo, as telenovelas reproduzem esquemas para figurar sentidos da imortalidade e da reencarnação em favor do amor romântico. Na narrativa, o melodrama se adapta aos propósitos de não posicionar a morte como entrave aos planos do amor idealizado pelos protagonistas, obedecendo a crenças vinculadas ao mito do amor romântico - caracterizado por uma lógica passional do amor cortês com papéis bem delimitados para cada gênero (BRAGANÇA, 2007).

As ressignificações da morte, evocando seres espirituais, reencarnações e mundos transcendentais, permeiam o imaginário religioso brasileiro como um todo, o que justifica suas ocorrências. A morte como salvação, promessa de compensação sublime pelas agruras suportadas, tem aqui dupla função: atende ao imaginário religioso de alcance das benesses num plano transcendental, de acesso a recompensas no além-mundo; e atende ao imaginário melodramático, pois permite que os personagens centrais não se desencontrem no desenrolar das narrativas ficcionais e conclamem o amor duradouro mesmo em outras dimensões.

O mistério da morte nas telenovelas espíritas não segue esquemas clássicos como “Quem matou Lineu?” e "Quem matou Odete Roitman?”, em que há a constatação de um crime e a busca pelo culpado, movimentando o arco dramático em torno do suspense. Nas telenovelas espíritas, não há aura de mistério em torno da morte dos personagens, pois eles ora seguem para o plano espiritual (A Viagem, Alma Gêmea) ora assumem novas vidas (Alma Gêmea, Além do Tempo). A morte deixa de ser "problema" - entendendo o termo como um fator condutor das narrativas - e passa a ser "solução" para estes enredos, em que o espectador vai se familiarizando com novos regimes visuais que, por mais inovadores pareçam, não se afastam das convenções de gênero. Pelo contrário, são empregadas justamente para revalidar o mote melodramático do amor feliz e duradouro.

Nas três tramas, grutas, cavernas e penhascos estão entre a paisagem onde o cósmico e/ou espiritual se expressa, um espiritual obscuro, nebuloso e de difícil apreciação quando se trata da crença em outras vidas, em reencarnação. Mesmo que o final feliz seja alçado a nova temporalidade, num novo espaço, ainda é algo reservado a profundos debates culturais e religiosos que não estão às claras, por isso a figuração de espaços rochosos, cavernosos e restritos apresentam com pertinência os debates das questões espirituais. 
Antes de serem telenovelas espíritas, estas obras são telenovelas, e tal afirmação diz das expectativas do gênero televisivo como balizadores para a produção e o consumo destes textos. Atendidas as premissas do gênero telenovela e sua base no melodrama, a camada de sentido associada ao espiritismo se acopla à estrutura narrativa e esta pode ser uma das razões para se entender a adesão às tramas. A audiência reconhece marcas que lhe satisfazem em torno do gênero e compreende arcos, tessituras e tramas. Os sentidos da morte são acionados por meio do universo religioso e se organizam como uma estratégia de comunicabilidade adotada pelo gênero telenovela a fim de fornecer as bases compensatórias ao público.

No entanto, as reconfigurações na telenovela obedecem a preceitos mercadológicos, empresariais e sociais, de modo a não ferir parâmetros cristalizados no modus operandi da ficção. Inovações são bem-vindas e repaginam o universo ficcional, guardadas as proporções das origens do melodrama. Por isso, o que parece evidente em termos televisuais nas telenovelas espíritas é uma primeira fase de aspectos instrucionais-didáticos, com replicações de esquemas em torno de crenças espiritualistas. A Viagem e Alma Gêmea abordaram a espiritualidade de maneira a desbravar o tema no campo ficcional, enquanto Além do Tempo sinalizou uma apropriação inovadora, com rupturas estilísticas e inserção de novos esquemas para abordar religiosidade na TV. Assim, estas telenovelas espíritas destacam o resgate espiritual após subsequentes expiações para se atingir um aprendizado catártico regado pelo sentimento reconfortante do final feliz.

\section{REFERÊNCIAS}

BALTAR, Mariana. Realidade Lacrimosa: o melodramático no documentário brasileiro contemporâneo. Niterói: EDUFF, 2019.

BERGER, Peter. A dessecularização do mundo: uma visão global. Religião e Sociedade, v.21, n.1, 2001, p. 9-23.

BITTENCOURT FILHO, José. Matriz religiosa brasileira: religiosidade e mudança social. Petrópolis: Vozes, 2003.

BRAGANÇA, Maurício de. Melodrama: notas sobre a tradição/tradução de uma linguagem revisitada. Eco-pós, v.10, n.2, jul-dez 2007, p. 29-47.

BROOKS, Peter. The Melodramatic Imagination: Balzac, Henry James, Melodrama and the Mode of Excess. New Haven-London: Yale University Press, 1995.

BUTLER, Jeremy. Television Style. New York: Routledge, 2010.

CUNHA, Magali do Nascimento. Os processos de midiatização das religiões no Brasil e o ativismo político digital evangélico. Famecos, v.26, n.1, 2019, p. 1-20. 
DAMAZIO, Sylvia. Da elite ao povo: advento e expansão do espiritismo no Rio de Janeiro. Rio de Janeiro: Bertrand Brasil, 1994.

ESPIRITISMO - Números materializados. Revista Superinteressante. 28 de maio de 2012. Online. Disponível em https://super.abril.com.br/historia/espiritismo-numeros-materializados/. Acesso em 7 mai. 2021.

GIUMBELLI, Emerson. O cuidado dos mortos: uma história da condenação e legitimação do espiritismo. Rio de Janeiro: Arquivo Nacional, 1997.

HERLINGHAUS, Herman (ed.). Narraciones anacrónicas de la modernidad. Melodrama y intermedialidad en América Latina. Santiago: Editorial Cuarto Propio, 2002.

HERLINGHAUS, Herman. Descentramiento hermenéutico, hibridación conceptual y conciencia histórica: una propuesta latinoamericana por asumir. In: MORAÑA, Mabel (ed). Nuevas perspectivas desde/sobre América Latina: el desafio de los estudios culturales. Santiago: Editorial Cuarto Propio, 2000, p. 97-105.

IBGE - INSTITUTO BRASILEIRO DE GEOGRAFIA E ESTATÍSTICA. Censo demográfico. 2010. Disponível em http://www.censo2010.ibge.gov.br/. Acesso em 7 mai. 2021.

KARDEC, Allan. O que é o espiritismo. 70ª ed. Araras: IDE, 2007.

LEWGOY, Bernardo. Os espíritas e as letras: um estudo antropológico sobre cultura escrita e oralidade no espiritismo kardecista. Tese (Doutorado) - Universidade de São Paulo, São Paulo, 2000.

LOPES, Maria Immacolata Vassalo de (org). Telenovela: Internacionalização e interculturalidade. São Paulo: Edições Loyola, 2004.

MARTIN-BARBERO, Jesús. Dos meios às mediações: comunicação, cultura e hegemonia. Trad. Ronald Polito e Sérgio Alcides. $7^{\text {a }}$ ed. Rio de Janeiro: Editora da UFRJ, 2013.

MARTIN-BARBERO, Jesús; REY, Germán. Os exercícios do ver: hegemonia audiovisual e ficção televisiva. Trad. Jacob Gorender. São Paulo: Editora Senac São Paulo, 2001.

MARTÍN-BARBEO, Jesús; MUÑOZ, Sonia (org). Televisión y melodrama: géneros y lecturas de la telenovela en Colombia. Bogotá: Tercer Mundo Editores, 1992.

MITCHELL, William John Thomas. Teoría de la imagen: ensayos sobre representación verbal y visual. Trad. Yaiza Hernández Velázquez. Madri: Ediciones Akal, 2009.

MONSIVÁIS, Carlos. El melodrama: "No te vayas, mi amor, que es inmoral llorar a solas". In: HERLINGHAUS, H (ed.). Narraciones anacrónicas de la modernidad. Melodrama y intermedialidad en América Latina. Santiago: Editorial Cuarto Propio, 2002, pp. 105-123.

OTT, Michaela. El discurso de lo melodramático. Entre Cristianismo, psicoanálisis y cine. In: HERLINGHAUS, H. (ed.). Narraciones anacrónicas de la modernidad. Melodrama y intermedialidad en América Latina. Santiago: Editorial Cuarto Propio, 2002, pp. 245-279.

ROCHA, Simone Maria. Análise da televisualidade e proposições sobre o regime estético televisivo. In: ROCHA, Simone Maria; FERRARAZ, Rogério (orgs.). Análise da ficção televisiva: metodologias e práticas. Florianópolis: Insular, 2019, p. 27-51.

ROCHA, Simone Maria; ALVES, Mateus Couto; OLIVEIRA, Lívia Fernandes de. A história através do estilo I: a Revolta da Vacina na telenovela Lado a Lado. In: ROCHA, S. M. (org.). Estilo televisivo e sua pertinência para a TV como prática cultural. Florianópolis: Insular, 2016. 
ROCHA, Cristina; VASQUEZ, Manuel. O Brasil na nova cartografia global da religião. Religião e Sociedade, v. 34, n.1, 2014, p. 13-37.

STOLL, Sandra Jacqueline. Espiritismo à brasileira. São Paulo: Editora da Universidade de São Paulo; Curitiba: Editora Orion, 2003.

WILLIAMS, Raymond. Televisão: tecnologia e forma cultural. Trad. Marcio Serelle e Mário Viggiano. São Paulo: Boitempo; Belo Horizonte, MG: PUC Minas, 2016.

\section{Telenovelas}

ALÉM DO TEMPO. Novela de Elizabeth Jhin. Escrita por Elizabeth Jhin, com colaboração de Eliane Garcia, Lílian Garcia, Duba Elia, Vinícius Vianna, Wagner de Assis e Renata Jhin. Direção geral: Pedro Vasconcelos. Elenco: Aline Moraes, Rafael Cardoso, Paolla Oliveira, Ireve Ravache, e outros. Rio de Janeiro, 18h, 13 de julho de 2015 a 15 de janeiro de 2016, 161 capítulos.

ALMA GÊMEA. Novela de Walcyr Carrasco. Escrita por Walcyr Carrasco, com colaboração de Thelma Guedes. Direção geral: Jorge Fernando. Elenco: Eduardo Moscovis, Priscila Fantin, Flávia Alessandra, Elizabeth Savalla, Ana Lúcia Torre e outros. Rio de Janeiro, 18h, de 20 de junho de 2005 a 10 de março de 2006, 227 capítulos.

A VIAGEM. Novela de Ivani Ribeiro. Escrita por Ivani Ribeiro, com colaboração de Solange Castro Neves. Direção geral: Wolf Maya. Elenco: Cristiane Torloni, Antônio Fagundes, Maurício Mattar, Lucinha Lins, Laura Cardoso e outros. Rio de Janeiro, 19h, 11 de abril a 21 de outubro de 1994, 167 capítulos.

\section{Original recebido em: 03 de dezembro de 2020 \\ Aceito para publicação em: 21 de julho de 2021}

Marcos Vinicius Meigre e Silva

Doutorando e mestre em Comunicação Social pela Universidade Federal de Minas Gerais. Jornalista graduado pela Universidade Federal de Viçosa. Membro do Grupo de Pesquisa Comunicação e Cultura em Televisualidades - COMCULT/UFMG.

\section{Simone Maria Rocha}

Professora Associada do Departamento de Comunicação Social da Universidade Federal de Minas Gerais. Líder do Grupo de Pesquisa Comunicação e Cultura em Televisualidades COMCULT/UFMG. Bolsista de produtividade do CNPq.

\section{(2) $\odot \Theta \odot$}

Esta obra está licenciada com uma Licença

Creative Commons Atribuição-NãoComercial-CompartilhaIgual 4.0 Internacional 